\title{
OPEN ACCESS NECK LUMP CLINIC
}

\section{A Kochhar, Clinical Assistant; A Usanov, locum Staff Grade; ME Baraka, Consultant; CH Bulman, Consultant, ENT; J Brunton, Consultant Radiologist, Royal Lancaster Infirmary}

\section{INTRODUCTION}

The patient presenting with a mass in the neck is a common occurrence in general practice. The presence of any lump can cause concern to both the patient and the doctor. These patients with lumps in the neck can find themselves in one of a number of outpatient clinics, including general surgery, oral surgery, plastic surgery and ENT. Such diversity of referral is no longer acceptable.

A recurring problem is the patient with an occult primary carcinoma in the upper aerodigestive tract who is referred to the otolaryngologist after a lymph node from the neck containing squamous cell carcinoma has already been excised. This is inappropriate management ${ }^{(1)}$ and delays diagnosis of the primary lesion, increases patient morbidity ${ }^{(2)}$ and may also jeopardise longterm survival ${ }^{(3,4,5)}$. We set up a neck lump clinic to enable patients with neck masses to be seen early, and to undergo a one-stop specialist evaluation (along with assessment of upper air and food passages), fine needle aspiration cytology, if needed, and an ultrasound scan. All patients referred with the presenting symptoms of a lump in the neck are seen by the ENT consultants on every Monday afternoon on the ENT ward at the Royal Lancaster Infirmary. The clinic has yielded a wide variety of benign and malignant pathology. The first 50 patients are discussed and evaluated.

\section{PATIENTS AND METHODS}

The clinic was opened to referrals from all general practitioners and hospital departments in January 2000. Any patient whose primary presenting complaint was a neck mass was referred directly to either of the ENT consultants and was seen within two weeks. Thyroid lumps are not included as these are currently managed by the general surgeons.

At the neck lump clinic, the history of the lump is taken, as well as the general history, and specific questions are asked about symptoms arising in the upper air and food passages, such as hoarseness and dysphagia. Clinical examination is performed and the neck, ear, nose and throat are routinely examined along with any other system as indicated by the history. Flexible nasolaryngology is performed in all patients. An ultrasound scan and fine needle aspiration cytology (FNAC) are performed for those patients whose diagnosis was not obvious on clinical grounds alone. Other investigations, such as further radiological tests, are arranged as necessary. The patient is reviewed a week later with the results.

\section{RESULTS}

Fifty patients were seen in the clinic between January and September 2000 , of whom 30 were male and 20 female. The patients were aged between three and 83 years, with the majority $(70 \%)$ being between 30 and 70 years. The diagnoses are detailed in Table 1.

\begin{tabular}{|c|c|c|c|}
\hline STRUCTURE & PATHOLOGY & NUMBER & \\
\hline \multirow[t]{5}{*}{ Lymph node } & benign/reactive & 15 & \\
\hline & SCC head and neck & \begin{tabular}{l}
\multicolumn{1}{c}{6} \\
metastases from tonsil \\
pyriform fossa \\
lateral pharynx \\
supraglottis
\end{tabular} & $\begin{array}{l}3 \\
1 \\
1 \\
1\end{array}$ \\
\hline & SCC occult primary & 1 & \\
\hline & Hodgkin's lymphoma & 2 & \\
\hline & non-Hodgkin's & 1 & \\
\hline \multirow[t]{4}{*}{ parotid gland } & pleomophic adenoma & 2 & \\
\hline & Warthins tumour & 1 & \\
\hline & abscess & 1 & \\
\hline & inflammatory & 1 & \\
\hline \multirow[t]{3}{*}{ submandibular gland } & pleomoprhic adenoma & 1 & \\
\hline & calcification & 1 & \\
\hline & sialadenitis/inflammation & 8 & \\
\hline \multirow[t]{4}{*}{ miscellaneous } & thyroglossal cyst & 4 & \\
\hline & branchial cyst & 1 & \\
\hline & cellulitis & 1 & \\
\hline & sarcomca & 1 & \\
\hline no abnormality & & 3 & \\
\hline
\end{tabular}

Table 1 Conditions identified in the first fifty neck lumps

Half of the referrals ( 25 patients) were referred because of enlarged lymph nodes. In eight patients $(16 \%)$ malignancy was detected. Six of these patients had a squamous cell carcinoma from a primary tumour in the larynx or pharynx. Three of them had metastasis from the tonsil and one each from the pyriform fossa, lateral pharyngeal wall and supraglottis. The seventh patient had a true occult myoepithelial carcinoma and the primary lesion could not be found. One patient had a huge swelling originating in the neck

\begin{tabular}{|l|c|}
\hline PROCEDURE & NUMBER \\
\hline pharyngolaryngoscopy & 10 \\
\hline excision biopsy & 9 \\
\hline radical neck dissection & 3 \\
\hline cistrunks (thyroglossal cyst excision) & 3 \\
\hline tonsillar biopsy & 3 \\
\hline tonsillectomy & 2 \\
\hline parotidectomy & 3 \\
\hline submandibular gland excision & 4 \\
\hline incision and drainage of parotid abscess & 1 \\
\hline branchial cyst excision & 1 \\
\hline
\end{tabular}

Table 2 Surgical procedures performed on patients presenting to the clinic 
and extending to the mediastinum and displacing the trachea. Fine needle aspiration suggested this to be sarcoma. He was referred to the cardiothoracic surgeons for further management. Three patients had lymphoma. The remaining 15 patients had reactive lymphadenopathy.

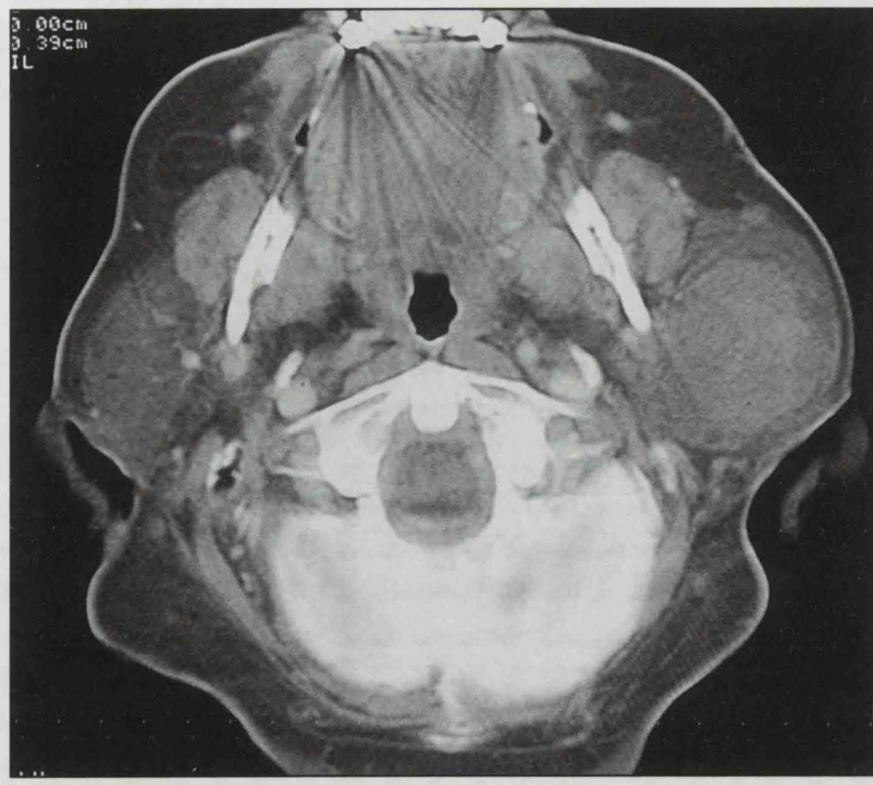

CT scan showing a localised mass in the superficial lobe of the left parotid gland

Fifteen patients had lumps arising from the salivary glands, five of them originating in the parotid gland and ten in the submandibular gland. Seven patients had miscellaneous lesions, four being thyroglossal cysts and one a branchial cyst. One patient had a recurring dramatic neck swelling postradiation and this was diagnosed as cellulitis. Three patients had no abnormal lump and normal structures such as the carotid artery, sternomastoid muscle and lateral process of the cervical vertebra were reasons for referral.

Ten patients had a fine needle aspiration cytology, of which three were equivocal. Thus, seven patients had a diagnosis of their condition by FNAC alone. Ten patients needed to have a chest X-ray and two patients an OPG film.

Thirty-six patients had an ultrasound scan and the role of this radiological investigation is discussed later. Six patients underwent a CT scan and one patient had an MR scan.

Twenty-five patients required various forms of surgery. The most commonly performed procedures were those of excision biopsy and panendoscopy of the upper aerodigestive tract with or without biopsy (Table 2). Of the nine neck lumps excised, three were lymphomas and one an occult primary cancer. Three patients had benign or reactive nodes excised. Seven patients with salivary gland swellings were operated on: three had a superficial parotidectomy and four had submandibular gland excision. Only one patient had a branchial cyst diagnosed and this was subsequently excised.

\section{DISCUSSION}

A wide spectrum of disease can present with a neck lump. The diagnosis may be difficult. The idea of setting up a clinic specifically for patients with a palpable neck lump is an attempt to rationalise referral patterns. Once referred, the patient will be seen by a consultant ENT surgeon within two weeks. By combining clinical examination with appropriate investigations a diagnosis of the neck lump was made on an outpatient basis for most patients.
An important part of the clinic is the initial assessment of the upper aerodigestive tract by flexible nasolaryngology. In a patient with an enlarged cervical node a thorough search must be carried out to rule out a primary head and neck cancer. Seven out of 50 patients presented with metastatic lymph node malignancies. Four of these were identified at the initial consultation. In two patients the primary was identified after a pharyngolaryngoscopy under general anaesthetic. The seventh patient had a myoepithelial carcinoma and no primary could be identified. He remains well and is under close follow-up.

The two investigations widely used are ultrasound and fine needle aspiration cytology. Thirty-six of our patients had an ultrasound scan of the neck. It is helpful in confirming the anatomical structure in which the lesion is found, whether it is single or multiple, cystic or solid and its relation to other normal anatomical structures such as the major vessels. Enlarged lymph nodes were the most common reason for referral, the concern being whether the underlying cause was malignancy. Ultrasound has been demonstrated to be a sensitive diagnostic tool for distinguishing between benign and malignant lymph nodes as small as $10 \mathrm{~mm}^{(6)}$. It has been shown that the long to short axis ratio on ultrasound scanning is an excellent criterion for differentiation between benign and malignant cervical lymphadenopathy. Those nodes with a long to short axis ratio of more than two can be correctly diagnosed as benign and those with a ratio of less than two can be correctly identified as malignant in $95 \%$ of $\operatorname{cases}^{(7)}$. The sonographic picture is also helpful in differentiating lymphomas from other causes of cervical lymphadenopathy. The nodal distribution patterns, along with distal enhancement and a lack of central nodal necrosis, point towards a diagnosis of lymphoma ${ }^{(8)}$. The use of ultrasound guidance when performing fine needle aspiration cytology has been clearly demonstrated to improve diagnostic accuracy, especially where the lesion is a small, mobile lymph node ${ }^{(9)}$. This emphasises the value of having a dedicated head and neck radiologist perform the scans.

With a troublesome neck mass, especially in an adult, fine needle aspiration cytology is an essential tool, as the information yield is high. In some patients it was possible to reassure them and discharge them on the basis of the FNAC. In some series of previously published reports up to $33 \%$ of samples taken at FNAC have been found to be unsatisfactory. Hence core needle biopsy has been suggested but carries the risk of seeding ${ }^{(10)}$. McGurk et $a l^{(11)}$ reported that in salivary gland lesions a preoperative diagnosis does not alter the management and hence FNAC need not be performed. Other authors advocate the use of FNAC preoperatively as this can distinguish between benign and malignant disease ${ }^{(5)}$. In all our patients with a confirmed salivary gland lump, FNAC was performed. This helps with preoperative counselling and with operative planning. For example, one of our patients with Warthins tumour elected not to proceed to surgery. Knowing the diagnosis of a pleomorphic adenoma before surgery directs the surgeon to use a wide margin of resection, thus reducing the chances of recurrence. Also, with the increased incidence of malignancy in tumours of the submandibular gland and the improved survival with more radical surgery, a preoperative FNAC would be helpful ${ }^{(2)}$. One patient had a branchial cyst and a preoperative FNAC was helpful in distinguishing a benign lesion from a malignant lymph node masquerading as a simple branchial cyst ${ }^{(3)}$. Only three benign lesions were excised.

Thirty-six percent of our patients had either reactive lymphadenopathy $(30 \%)$ or no abnormality $(6 \%)$. The majority of patients in the first group had lymphadenopathy secondary to an upper respiratory tract infection. In the others 
a normal anatomical structure was mistaken for a lump, eg carotid artery, lateral process of a cervical vertebra or sternomastoid muscle.

The benefits of this clinic are many. An accurate diagnosis can be reached on the vast majority of patients on an outpatient basis. Further definitive management can be arranged without delay. Urgent referrals should be directed to the ENT department at the Royal Lancaster Infirmary.

\section{Acknowledgments}

The authors wish to express their gratitude to the following people: Sharon Timperley, superintendent radiographer; Deborah Crawford, superintendent radiographer; Toni Bell, ward clerk, ward 31; Mary Evans, secretary to Mr Baraka.

\section{REFERENCES}

1 Gianoli GJ, Miller RH. Cervical node biopsy. J Lane State Med Soc 1992;144(3):91-94

2 London J, London NJ, Kay SP. Iatrogenic accessory nerve injury. Ann Roy Coll Surg Engl 1996;78(2):146-150

3 Ellis ER, Rao PV, McCarty PJ, Parsons JT, Mendenhall WM, Stringer SP, Cassissi NJ, Million RR. Incisional or excisional neck node biopsy before definitive radiotherapy, alone or followed by neck dissection. Head and Neck 1991;13(3):177-183

4 Mack Y, Parsons JT, Mendenhall WM, Stringer SP, Cassissi NJ, Million RR. Squamous carcinoma of the head and neck: management after excisional biopsy of a solitary metastatic neck node. Int J Radiat Oncol, Biol, Physics 1993;25(4):619622

5 Vowles RH, Ghiacy S, Jefferis AF. A clinic for the rapid processing of patients with neck masses. J Laryngol and Otol 1998;112:1061-1064

6 Kruyt RH, van Putten WL, Levendag PC, de Boer MF, Oudkerk M. Biopsy of non-palpable cervical nodes: selection criteria for ultrasound guided biopsy in patients with head and neck squamous carcinoma. Ultrasound in Med and Biol 1996;22(4):413-419

7 Steinkamp HJ, Cornehl M, Hosten N, Pegios W, Vogl T, Felix R. Cervical lymphadenopathy: ratio of long to short axis diameter as a predictor of malignancy. $\mathrm{Br} \mathbf{J}$ Radiol 1995;68:266-270

8 Ahuja A, Ying M, Yang WT, Evans R, King W, Metreweli C. The use of sonography in differentiating cervical lymphomatous lymph nodes from cervical metastatic lymph nodes. Clin Radiol 1996;51(3):186-190

9 Van den Brekel MWM, Castelijns JA, Stel HV, Golding RP, Meyer CJL, Snow GB. Modern imaging techniques and ultrasound-guided aspiration cytology for the assessment of neck node metastases: a prospective comparative study. Eur Arch Otolaryngol 1993;250:11-17

10 Smith OD, Ellis PDM, Bearcroft PWP, Berman LH, Grant JW, Jani P. Management of neck lumps - a triage model. Ann Roy Coll Surg Engl 2000;82:223-226

11 McGurk M, Hussain K. Role of fine needle aspiration cytology in the managment of the discrete parotid lump. Ann Roy Coll Surg Engl 1997;79:198-202

12 Spiro RH, Armstrong J, Harrison L, Geller NL, Lin SY, Strong EW. Carcinoma of major salivary glands: recent trends. Arch Otolaryngol, Head and Neck Surg 1989;115:316321

13 Flanagan PM, Roland NJ, Jones AS. Cervical node metastases with features of branchial cyst. J Laryngol and Otol 1994;108:1068-1071 